\title{
Reabsorbable Pins can Reinforce an Early Sternal Stability After Median Sternotomy in Young Children with Congenital Heart Disease
}

\author{
Chengming Fan ${ }^{1}\left(\mathbb{D} \cdot \mathrm{Mi}_{\mathrm{Tang}}{ }^{1} \cdot\right.$ Sijie $\mathrm{Wu}^{1} \cdot$ Shuwen Yuan ${ }^{2} \cdot$ Anton V. Borovjagin $^{3} \cdot$ Jinfu Yang $^{1}$
}

Received: 28 May 2019 / Accepted: 16 August 2019 / Published online: 23 September 2019

๑) Springer Science+Business Media, LLC, part of Springer Nature 2019

\begin{abstract}
We evaluated the efficacy of bioresorbable sternal reinforcement device (poly-L-lactide sternal pins) on sternal healing after median sternotomy in young children (with body weight less than $10 \mathrm{~kg}$ ) with congenital heart disease (CHD). Data from 85 patients, who underwent CHD surgery through median sternotomy from October 2016 to May 2018, were collected and analyzed. Sternal pins were utilized in 85 patients $(10 \mathrm{~mm} \times 1 \mathrm{~mm} \times 1 \mathrm{~mm}$ for patients with body weights less than $5 \mathrm{~kg}$ and $15 \mathrm{~mm} \times 2 \mathrm{~mm} \times 2 \mathrm{~mm}$ for those weighing between 5 and $10 \mathrm{~kg}$ ) in addition to sternum closure with Ethicon PDS ${ }^{\mathrm{TM}} \mathrm{II}$ running sutures (Group A), while 84 patients received the Ethicon sternal closure (Group B) with no pins. The occurrence of sternal dehiscence, anterior-posterior displacement, and high-low displacement was evaluated by physical examination and three-dimensional computed tomography at one month postoperatively. No anterior-posterior sternal displacement $(0 \%)$ was observed in Group A, while 10 anterior-posterior displacements (11.9\%) were observed in Group B $(P<0.01)$. The number of sternal caudal-cranial displacements in Groups A and B was $4(4.71 \%)$ and $5(5.35 \%)$, respectively $(P=0.870)$. While no sternal dehiscence (0\%) was observed in Group A, 7 out of 84 patients $(8.33 \%)$ in Group B exhibited obvious sternal dehiscence $(P<0.01)$. The bioresorbable poly-L-lactide sternal pins reduced an anterior-posterior sternal displacement and sternal dehiscence, which was accompanied by a significant improvement of an early sternal fixation.
\end{abstract}

Keywords Poly-L-lactide $\cdot$ Sternum $\cdot$ Chest wall $\cdot$ Wound healing $\cdot$ Congenital heart disease

\section{Introduction}

Sternal malunion following a median sternotomy in the young children with congenital heart disease (CHD) may lead to sternal infection, chronic osteomyelitis, or deformities of the sternum like pectus carinatum [1]. Although the absorbable polydioxanone (PDS) suture is a suitable material for sternotomy closure after pediatric open cardiac surgery

Electronic supplementary material The online version of this article (https://doi.org/10.1007/s00246-019-02212-1) contains supplementary material, which is available to authorized users.

Jinfu Yang

yangjinfu@csu.edu.cn

1 Department of Cardiovascular Surgery, The Second Xiangya Hospital, Central South University, Middle Renmin Road 139, Changsha 410011, China

2 Department of Radiology, The Second Xiangya Hospital, Central South University, Changsha, China

3 Department of Biomedical Engineering, University of Alabama at Birmingham, Birmingham, AL, USA
[2], achieving sufficient sternal fixation remains a challenge. Both inadequate and excessive tension of PDS may result in sternal dehiscence. The reliability of using PDS alone to close the sternum in adult is controversial [3-5]. Combining poly-(L-lactide) acid sternal pins with multifilament polydioxanone cord for closing the lower partial median sternum has been reported in older children undergoing less invasive cardiac surgery [6]. However, the differences in properties between the two types of sternal closures, in application for open cardiac surgery in young children, remain uncharacterized. Since October 2016, we have utilized the bioabsorbable poly-(L-lactide) acid sternal pins as auxiliary closure to PDS running suture for a median sternotomy in pediatric open heart surgery. In this study, we retrospectively compared the sternal stability and healing susceptibility of the two sternal closure types by using physical examination and threedimensional computed tomography in open cardiac surgery patients whose body weights were less than $10 \mathrm{~kg}$. 


\section{Methods}

A traditional open heart surgery on 169 CHD-diagnosed children with body weights under $10 \mathrm{~kg}$ was performed by a single surgeon using the same technique at the Second Xiangya Hospital of Central South University between October 2016 and May 2018 and the outcomes were evaluated retrospectively. After correction of the cardiac malformations, sternal closure on 85 patients was performed by using bioresorbable poly-L-lactide sternal reinforced device (Sternum Pin, Teijin Medical Technologies Co, Ltd, Osaka, Japan) in combination with the Ethicon polydioxanone PDS ${ }^{\mathrm{TM}}$ II (W9236T, Ethicon, Inc, Somerville, NY) running sutures (Group A), while Ethicon $\mathrm{PDS}^{\mathrm{TM}} \mathrm{II}$ cord sutures alone were used on another cohort of 84 patients (Group B). All patients were selected randomly. The preoperative patient profiles are shown in Table 1. No significant differences in preoperative characteristics were noted between the two groups of patients.

Table 1 The profiles of the patients preoperatively

\begin{tabular}{lllll}
\hline & Group A & Group B & Value & $P$ value \\
\hline Case $(n)$ & 85 & 84 & & \\
Gender (Male/ & $42 / 43$ & $39 / 45$ & $\mathrm{x}^{2}=0.151$ & 0.7 \\
$\quad$ female) & & & & \\
Age (month) & $10.46 \pm 3.22$ & $9.63 \pm 3.29$ & $\mathrm{t}=1.654$ & 0.1 \\
Body weight $(\mathrm{kg})$ & $7.15 \pm 1.16$ & $7.26 \pm 1.13$ & $\mathrm{t}=0.625$ & 0.533 \\
VSD $(n)$ & 30 & 29 & $\mathrm{x}^{2}=0.671$ & $>0.999$ \\
ASD $(n)$ & 5 & 5 & & \\
VSD + ASD (n) & 23 & 20 & & \\
ASD + PS $(n)$ & 6 & 7 & & \\
TOF $(n)$ & 12 & 13 & & \\
DORV $(n)$ & 2 & 2 & & \\
PAVSD $(n)$ & 2 & 2 & & \\
CAVSD $(n)$ & 1 & 1 & & \\
PAPVC $(n)$ & 1 & 2 & & \\
COA $(n)$ & 1 & 1 & & \\
CAF $(n)$ & 1 & 1 & & \\
Ebstein $(n)$ & 1 & 1 & &
\end{tabular}

$V S D$ ventricular septal defect, $A S D$ atrial septal defect, $P S$ pulmonary stenosis, TOF tetralogy of fallot, DORV double outlet of right ventricular, $P A V S D$ partial atrioventricular septal defect, CAVSD complete atrioventricular septal defect, $P A P V C$ partial anomalous pulmonary venous connection, $C O A$ coarctation of the aorta, $C A F$ coronary artery fistula

\section{Surgical Procedure}

All the enrolled patients underwent a cardiopulmonary bypass surgical procedure through the median sternotomy. After all the cardiac defects were repaired, two suitable bioresorbable sternal pins $(10 \mathrm{~mm} \times 1 \mathrm{~mm} \times 1 \mathrm{~mm}$ for patients with body weight of less than $5 \mathrm{~kg}$, or $15 \mathrm{~mm} \times$ $2 \mathrm{~mm} \times 2 \mathrm{~mm}$ for those with body weight from 5 to $10 \mathrm{~kg}$ ) were selected for Group A patients (Fig. 1a). Two symmetrical pairs of small holes in the cut surfaces of each sternal halves were made with an accessory reamer: one pair in the manubrium and the other pair in the sternal body. One pin was inserted into the medullary hole on one side of sternum right after the PDS standard running suture (Fig. 1b, arrows) by $1 / 3$ of its length, whereas another $1 / 3$ of the pin was inserted into the hole on the other side of the sternum (Fig. 1c, arrows), followed by tightening the PDS sutures. The sternum closures were completed by further tightening the PDS cord (Fig. 1d). In Group B patients, only a standard closure with PDS running suture was performed. All the children in this study were discharged uneventfully on postoperative days $8-15$. All patients were evaluated by a routine physical examination both at discharge and 4 weeks after the surgery. Front and lateral chest radiography and CT scanning were performed 4 weeks postoperatively to evaluate the outcomes of cardiac repair as well as the sternum union. Evaluators were blinded to the type of closure used in each case.

\section{Statistical Analysis}

Data are expressed as mean \pm SE. All statistical calculations were performed using the Statistical Product and Service Solutions 14.0 software (SPSS Institute). Independent sample $t$ test, $\mathrm{X}^{2}$ test, or Fisher's exact test was performed to determine differences between the groups. The critical alpha level for these analyses was set at $P<0.05$.

\section{Results}

The mean bypass and cross clamp times, postoperative ventilator support time, the duration of stay in the intensive care unit (ICU), and postoperative residence time were not significantly different between the Group A 

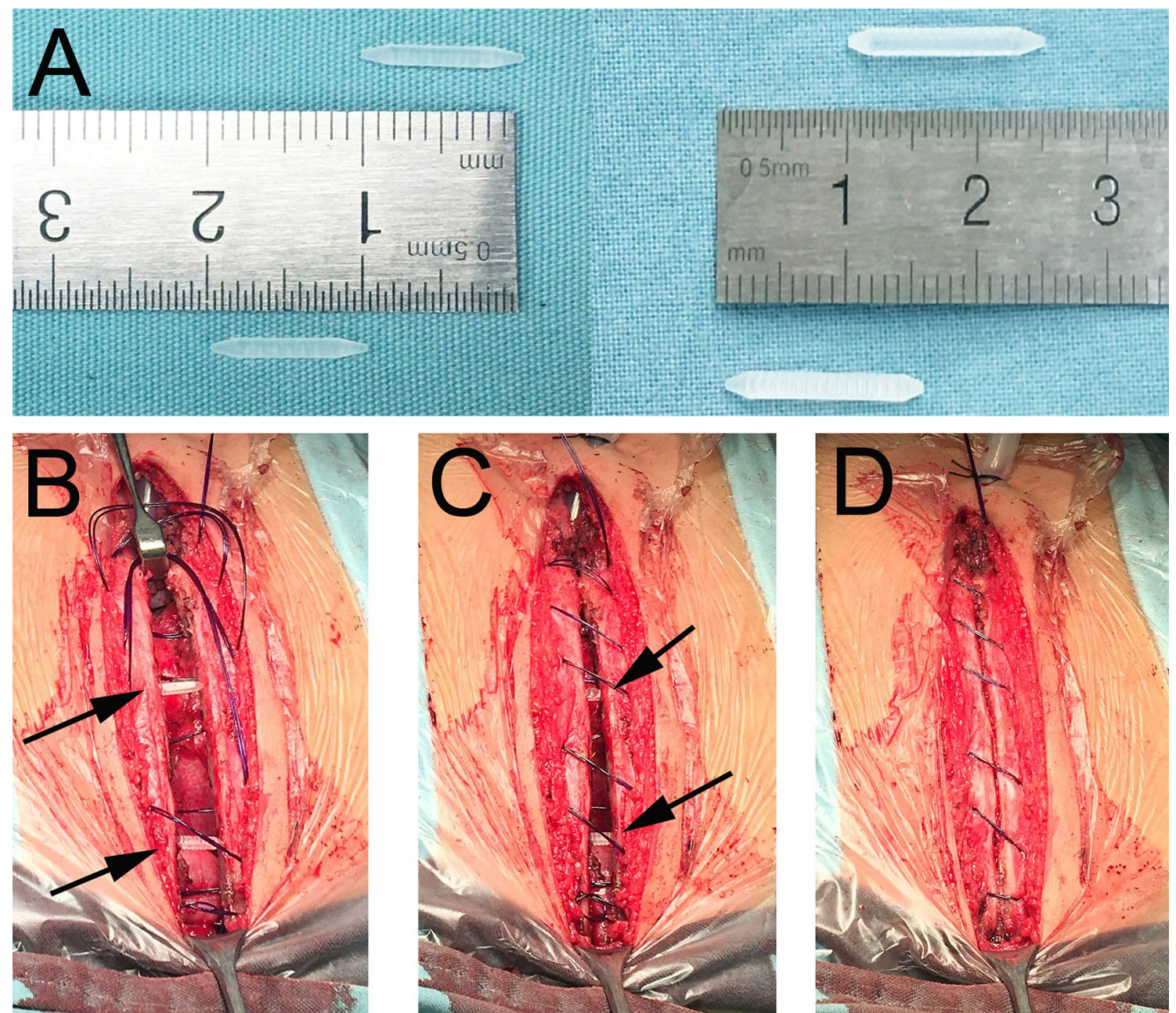

Fig. 1 Surgical procedure of the sternal closure. a A suitable pin was selected according to the body weight; b $1 / 3$ length of the pins were inserted into the left side hole of the sternum; $\mathbf{c}$ another 1/3 length of the pins were inserted into the right side hole of the sternum; $\mathbf{d}$ tightening the PDS cord and complete the sternal closure

presenting mild sternal caudal-cranial displacement. In Group B, the number of patients with sternal caudal-cranial displacement (Fig. 4a, b, Video 2) was $5(5.35 \%$ ), while $10(11.9 \%)$ patients exhibited a sternal displacement with the skin raised in the anterior-posterior direction (Fig. 4c, d, arrows, Video 3), and another 7 (8.33\%) patients presented a sternal dehiscence (Fig. 4e, f, Video $4)$. No anterior-posterior displacements or sternal dehiscence $(0 \%)$ were observed in Group A patients. No further surgical repair was needed in all these deformities during 
Fig. 2 Physical examination one month postoperative. a Anterior view of the chest from Group A; b right lateral view of the chest from Group A; c anterior view of the chest from Group B; d right lateral view of the chest from Group B
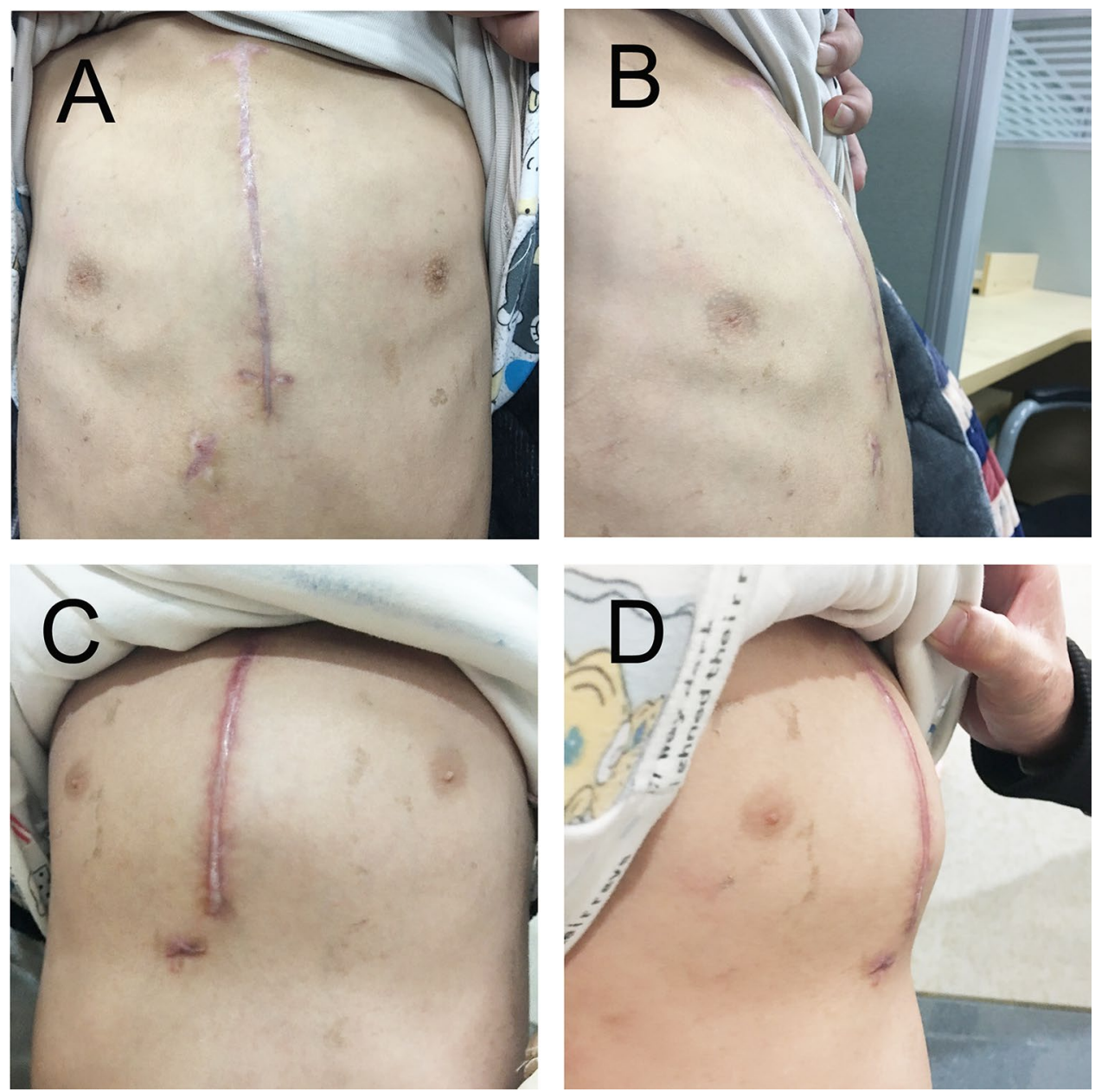

the follow-up period. No significant differences with regard to postoperative sternal dehiscence and displacements were found among the different diagnosis groups (Table 2).

\section{Discussion}

Median sternotomy is a current standard of care for open heart surgery procedures. Sternal displacement is a recognized complication after median sternotomy, occurring in $6.8-18.5 \%$ of cases $[7,8]$. Sternal displacements may be further complicated by infections, mediastinitis, pain, as well as compromised cardiac and pulmonary functions [9].
Although numerous methods for sternal osteosynthesis have been described [10,11], sternal closure techniques were rarely reported for open cardiac surgery in children, especially in young children. Pectus carinatum, also known as "pigeon chest," could result from non-infected sternal displacements in children after an open heart surgery. When these patients grow up, most of them become asymptomatic. However, some concerns about their body shape have been associated with low self-esteem and a mental quality of life [12]. Symptomatic patients may report compromised chest expansion/movement in areas of the deformed cartilage, often resulting in serious exercise intolerance [13].

PDS cord, with its biodegradability, has developed to a clinically compatible material for sternal closure after 
Fig. 3 Three-dimensional computed tomography in Group A 1 month postoperative. a Anterior view of the well-fused sternum; $\mathbf{b}$ posterior view of the sternum; c a smooth skin (arrows) and a symmetrical sternum were observed through the left side view and $\mathbf{d}$ the right side view
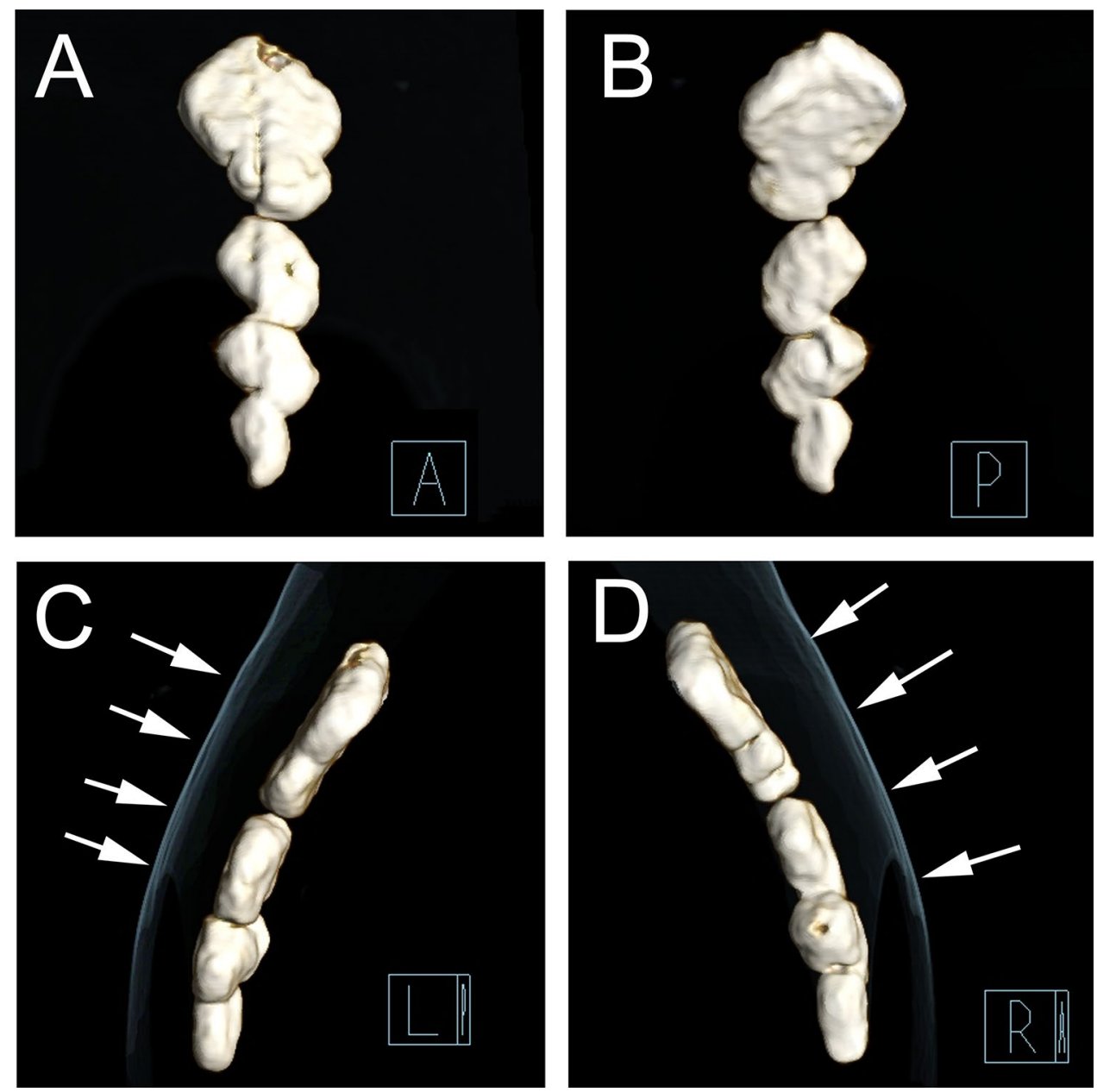

pediatric open cardiac surgeries [2, 14, 15]. However, Usui et al. found that PDS cord has insufficient reliability for securely closing the sternum. It has enough resistance to traction force, but could be damaged by shear stress from the bone edge [3]. Poly-L-lactide sternal pin has osteological bioactivity and is being gradually replaced with natural bone tissue that strengthens the patient's own sternum bone [16]. This bioabsorbable pin has been reported to significantly improve the stability of sternotomy closure in adults undergoing median sternotomy [8] and in older children undergoing a lower partial sternotomy [6].

In our study, we found that PDS cord supplemented with the sternal pins (Group A) as compared to PDS cord running suture alone (Group B) could reduce the incidence of sternal anterior-posterior displacement and sternal dehiscence. Without the pins, it is more difficult to achieve two separated surfaces of the sternum to cover each other. Because of the uneven stress, the sternum sides may tend to overlap (a displacement in anterior-posterior direction), and further form a pectus carinatum. The sternal pins can prevent the two sides of the sternum from slipping and separating by anchoring one side of the sternum to the other and directly contact with the sternum. We also observed sternal caudal-cranial displacement in both Group A and Group B patients and found no significant difference in its occurrence between the groups. We believe that this direction of displacement is due to the closure method of running suture which could result in a ramp downward tension (Fig. 1c, d). Substituting this running suture method for other 
Fig. 4 Three-dimensional computed tomography in Group B 1 month postoperative. A representative caudal-cranial displacement of the sternum was observed through the anterior view (a) and the posterior view of the sternum (b); an anteriorposterior displacement of the sternum and the skin raised in the same direction (arrows) were observed through the left side view (c) and the right side view (d); a representative sternal dehiscence was observed through the anterior view (e) and the posterior view (f)
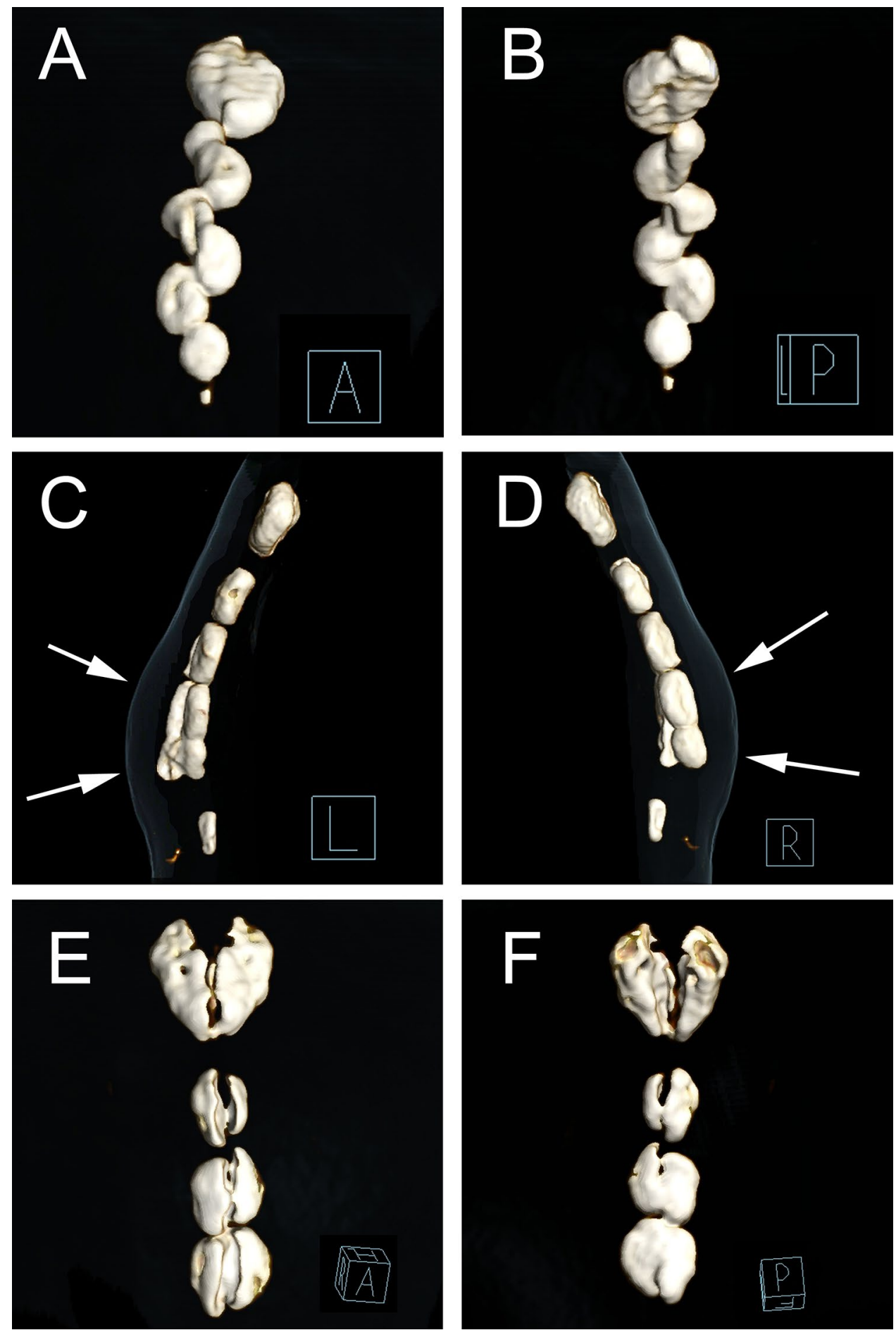

techniques such as interrupted suture or double-loop stitches may help avoiding those complications [5]. The primary limitation of this study was the short follow-up period, as longer follow-up periods are needed to allow reliably evaluating the effect of the sternal pin on long-term clinical outcomes.

\section{Conclusion}

The bioresorbable poly-L-lactide sternal pins can reduce an anterior-posterior sternal displacement and sternal dehiscence and strengthen an early sternal fixation in the young children after open cardiac surgery. 
Table 2 Sternal displacement incidence in the patients with different diagnosis postoperatively

\begin{tabular}{|c|c|c|c|c|c|c|}
\hline \multirow[b]{2}{*}{ Diagnosis } & \multicolumn{2}{|c|}{ Dehiscence } & \multicolumn{2}{|c|}{$\begin{array}{l}\text { Caudal-cranial displace- } \\
\text { ment }\end{array}$} & \multicolumn{2}{|c|}{$\begin{array}{l}\text { Anterior-posterior dis- } \\
\text { placements }\end{array}$} \\
\hline & Group A & Group B & Group A & Group B & Group A & Group B \\
\hline $\operatorname{VSD}(\%)$ & 0 & $5(6.94)^{*}$ & $6(8.11)$ & $7(9.72)^{\#}$ & 0 & $8(11.11)^{*}$ \\
\hline $\operatorname{ASD}(\%)$ & 0 & $1(8.33)^{*}$ & $1(7.70)$ & $1(8.33)^{\#}$ & 0 & $1(8.33)^{*}$ \\
\hline VSD + ASD (\%) & 0 & $3(7.50)^{*}$ & $4(9.76)$ & $4(10.00)^{\#}$ & 0 & $5(12.50)^{*}$ \\
\hline $\mathrm{ASD}+\mathrm{PS}(\%)$ & 0 & $1(6.67)^{*}$ & $1(6.25)$ & $1(6.67)^{\#}$ & 0 & $2(13.33)^{*}$ \\
\hline TOF (\%) & 0 & $2(7.14)^{*}$ & $2(7.70)$ & $2(7.14)^{\#}$ & 0 & $3(11.19)^{*}$ \\
\hline Total Number (\%) & 0 & $12(7.19)^{*}$ & $14(8.24)$ & $15(8.98)^{\#}$ & 0 & $19(11.38)^{*}$ \\
\hline$P$ value** & - & 0.9998 & 0.9941 & 0.9973 & - & 0.9987 \\
\hline
\end{tabular}

\#Not significant versus Group A

${ }^{*} P<0.01$ versus Group A

${ }^{* *}$ Fisher's exact test in contingency table analyses
Acknowledgements This study was supported by the Fundamental Research Funds for the Central Universities of Central South University (2017zzts234).

Author Contributions CF: data review, writing. MT: data collection. SW: data collection. SY: data collection. AB: data review, writing. JY: study design, paper final review.

\section{Compliance with Ethical Standards}

Conflict of interest All authors have declared no conflict of interest.

Ethical Approval The study was approved by the local Institutional Research Ethics Committee, which waived the need to obtain patient consent.

Informed Consent Informed consent was obtained from all individual participants included in the study.

\section{References}

1. Hu CX, Tan J, Chen S, Ding H, Xu ZW (2014) Comparison of clinical outcomes and postoperative recovery between two open heart surgeries: minimally invasive right subaxillary vertical thoracomy and traditional median sternotomy. Asian Pac J Trop Med 7:625-629

2. Keçeligil HT, Kolbakir F, Akar H, Konuralp C, Demir Z, Demirağ MK (2000) Sternal closure with resorbable synthetic loop suture material in children. J Pediatr Surg 35:1309-1311

3. Usui A, Oshima H, Akita T, Ueda Y (2006) Polydioxane (PDS) cord has insufficient reliability to securely close the sternum. J Thorac Cardiovasc Surg 131:1174-1175

4. Luciani N, Anselmi A, Possati G (2006) Adjusting the indication to polydioxane suture for elective sternal closure. J Thorac Cardiovasc Surg 132:1243-1244

5. Yang XN, Pastorino U (2006) Are absorbable sutures inadequate to close the sternum? J Thorac Cardiovasc Surg 132:1503
6. Oiwa H, Ishida R, Sudo K (2004) Sternal closure with reabsorbable pin and cord in pediatric-less invasive cardiac surgery. Ann Thorac Surg 78:358-359

7. Negri A, Manfredi J, Terrini A et al (2002) Prospective evaluation of a new sternal closure method with thermoreactive clips. Eur J Cardiothorac Surg 22:571-575

8. Tsunekawa T, Usui A, Oshima $\mathrm{H}$ et al (2012) A bioresorbable osteosynthesis device can induce an earlier sternal fusion after median sternotomy. Interact Cardiovasc Thorac Surg 15:377-381

9. Subramaniam T, Keita L, Veerasingam D (2015) Sternal Talon, a novel repair for sternal dehiscence. Kardiochir Torakochirurgia Pol 12:153-154

10. Song DH, Lohman RF, Renucci JD, Jeevanandam V, Raman J (2004) Primary sternal plating in high-risk patients prevents mediastinitis. Eur J Cardiothorac Surg 26:367-372

11. Bek EL, Yun KL, Kochamba GS, Pfeffer TA (2010) Effective median sternotomy closure in high risk open heart patients. Ann Thorac Surg 89:1317-1318

12. Steinmann C, Krille S, Mueller A, Weber P, Reingruber B, Martin A (2011) Pectus excavatum and pectus carinatum patients suffer from lower quality of life and impaired body image: a control group comparison of psychological characteristics prior to surgical correction. Eur J Cardiothorac Surg 40:1138-1145

13. Coskun ZK, Turgut HB, Demirsoy S, Cansu A (2013) Clinical experience of repair of pectus excavatum and carinatum deformities. Cardiovasc J Afr 24:318-321

14. Schwab RJ, Hähnel JC, Paek S, Meisner H, Sebening F (1994) Sternal closure with resorbable synthetic suture material in children. Thorac Cardiovasc Surg 42:185-186

15. Kreitmann B, Riberi A, Metras D (1992) Evaluation of an absorbable suture for sternal closure in pediatric cardiac surgery. J Card Surg 7:254-256

16. Oncel M, Tezcan B, Akyol KG, Dereli Y, Sunam GS (2015) Sternal closure with absorbable pins and cords in general thoracic surgery. Surg Today 45:929-931

Publisher's Note Springer Nature remains neutral with regard to jurisdictional claims in published maps and institutional affiliations. 